\title{
Predicción automática de la calidad del aceite de oliva virgen empleando visión por computador sobre aceitunas a la entrada del proceso de elaboración
}

\author{
O. Cáceres Moreno ${ }^{a}$, D.M. Martínez Gila ${ }^{a}$, D. Aguilera Puerto ${ }^{b}$, J. Gámez García $^{a}$ y J. Gómez Ortega ${ }^{a}$ \\ ${ }^{a}$ Grupo de Robótica, Automática y Visión por Computador de la Universidad de Jaén \\ ${ }^{b}$ Fundación Andaltec I + D + i \\ dmgila@ujaen.es
}

\section{Resumen}

Los parámetros más importantes para medir la calidad del aceite de oliva virgen (AOV) son la acidez y el índice de peróxidos y actualmente son determinados en laboratorios que utilizan las muestras de aceitunas extraídas de cada lote en el proceso de recepción de las almazaras. El objetivo de este trabajo es proporcionar un sistema de inspección automático, basado en visión por computador en los canales visible e infrarrojo (IR), para inferir automáticamente estos parámetros. La propuesta utiliza como características principales las diferencias de textura superficial, los defectos en las imágenes en IR y una valoración de color en el espacio CIELab. Por otra parte dos redes neuronales artificiales se han utilizado como técnica de estimación de los parámetros de calidad mencionados. El sistema ha alcanzado buenos resultados con $R=96.3$ para acidez y $R=93.9$ para índice de peróxidos.

Palabras clave: Control de la calidad del aceite de oliva virgen; Visión por computador; Control de calidad automático; Acidez; Índice de peróxidos.

\section{Introducción}

El aceite de oliva virgen es el zumo de la aceituna obtenido únicamente por procedimientos mecánicos o físicos bajo condiciones de temperatura controlada. La producción mundial total de aceite de oliva en 1993/1994 fue 1825.0 mil toneladas. Veinte años más tarde, en 2013/2014, la producción creció hasta 3270.5 mil toneladas [1]. Lo que significa un incremento significativo de la producción a la vez que representa la importancia de este sector.

La calidad del aceite de oliva extraído se puede relacionar con el estado agronómico de las aceitunas (índice de madurez, modo de recolección) y las condiciones de extracción de aceite de oliva (recepción de fruto, almacenamiento, molienda, batido, extracción y centrífuga). Muchos trabajos han estudiado estas relaciones [2] [3] [4] [5].
El control de la calidad del aceite de oliva se define en el Reglamento (CEE) $\mathrm{N}^{\circ} 2568 / 91$ y el Reglamento (UE) $\mathrm{n}^{\circ}$ 1348/2013 [6] que definen las características físico-químicas y organolépticas de los aceites de oliva, así como los métodos de evaluación de estos parámetros.

Aunque en el reglamento aparecen más parámetros, en este trabajo sólo dos de ellos han sido estudiados por su importancia. Éstos son la acidez y el índice de peróxido.

- Acidez: este parámetro cuantifica la cantidad de ácidos grasos libres en el aceite y se expresa en porcentaje de ácido oleico. La elevada presencia de estos ácidos grasos libres es un resultado negativo. Entre otros factores, su presencia se debe a las malas condiciones o al mal tratamiento del fruto. La regulación actual considera el límite de acidez para los aceites de oliva virgen extra en 0.8 grados.

- Índice de peróxido: este parámetro determina el grado de oxidación primaria de aceite de oliva y se mide en miliequivalentes $(\mathrm{mEq})$ de oxígeno activo por $\mathrm{kg}$ de aceite. El límite para un consumo seguro es 20. Las grasas se oxidan cuando entran en contacto con el oxígeno y los peróxidos se consideran los primeros productos de oxidación. Este índice también indica el deterioro de ciertos componentes de interés nutricional, como la vitamina E.

Normalmente la determinación de ambos parámetros se realiza en laboratorios acreditados mediante análisis químicos que siguen los reglamentos de la CE. Este procedimiento impide obtener información durante el proceso de elaboración del aceite de oliva al mismo tiempo que los trabajadores de las fábricas no pueden tomar ninguna decisión en cuanto a clasificación de aceitunas en función de los resultados de estos valores.

En [7] los autores evaluaron la importancia del proceso de clasificación de lotes de aceituna de acuerdo a la calidad del aceite extraído antes de entrar al proceso de extracción, concluyendo que se trata de un proceso crucial para producir el 

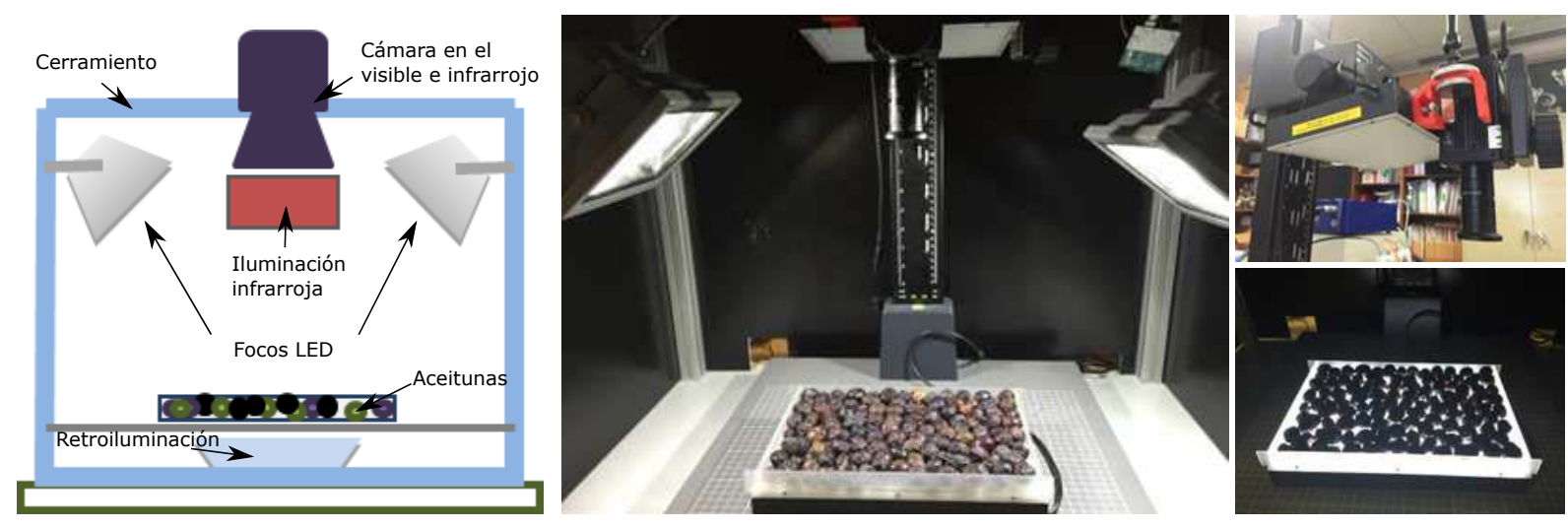

Figura 1: Sistema instalado para la adquisición de imágenes

máximo nivel de calidad y al mismo tiempo el máximo rendimiento posible.

Actualmente en el patio de las almazaras se realiza una primera clasificación de los lotes de aceituna entrantes de acuerdo a la inspección visual realizada por el operario de patio, que decide la categoría y la calidad de las aceitunas (aceitunas recogidas del árbol o del suelo, aceitunas defectuosas, índice de madurez, variedad, ...).

Principalmente se consideran dos categorías para la clasificación de lotes de aceitunas: aceitunas recolectadas del suelo y aceitunas recolectadas del árbol. En la primera categoría las aceitunas han caído al suelo antes de ser recogidas, por lo que contienen suciedad y desechos así como defectos en el aceite como son alta acidez, alto índice de peróxido y características organolépticas desfavorables [8]. En la segunda categoría entran las aceitunas recogidas directamente del árbol y la calidad del fruto está relacionada principalmente por factores como el índice de madurez o la metodología de recolección. El índice de peróxidos y la acidez tienden a aumentar en aceitunas maduras y a disminuir en frutos verdes.

El objetivo de este trabajo es proponer y evaluar una metodología off-line basada en visión por computador para la estimación automática de dos de los principales parámetros de calidad del aceite producido (acidez e índice de peróxidos) a partir de imágenes de aceitunas en el espectro visible e infrarrojo.

\subsection{Trabajos previos}

Las aplicaciones de visión por computador para la inspección y clasificación de productos alimenticios están ampliamente extendidas [9]. Esta tecnología se ha utilizado en diferentes fases del proceso de producción de aceite de oliva y de aceitunas de mesa. En [10], se propone un sistema automático de inspección aplicado a aceitunas de mesa que tiene en cuenta el color de la piel y la presencia de defectos superficiales. La tecnología de visión por computador también ha sido empleada para predecir el contenido de aceite en muestras de aceitunas [11] o para estimar el índice de madurez de los frutos [12]. En [13], se presenta un método de clasificación de aceitunas destinadas a la producción de aceite basado en visión infrarroja y considerando como principal característica el aspecto de la piel. Recientemente, en [15] los autores emplearon un sistema basado en visión por computador instalado en laboratorio para clasificar lotes de aceitunas procedentes de suelo y de vuelo.

Por otro lado, en [14] se desarrolló un sistema de visión por computador para la estimación de la acidez y del índice de peróxidos utilizando, en este caso, imágenes de aceitunas en los canales RGB e IR. Como entradas del sistema también se utilizaron parámetros del proceso de extracción tales como la temperatura de las aceitunas, la temperatura de la batidora, de la centrífugadora y del decánter. La metodología que se propone en este trabajo no necesita información de las variables de proceso y puede proporcionar indicadores de calidad al mismo tiempo que se recepciona la aceituna en la almazara antes de la extracción del aceite.

El documento se ha estructurado del siguiente modo: En primer lugar se exponen los materiales y los métodos utilizados para la experimentación; En segundo lugar se describen los resultados obtenidos; Y por último se presentan las conclusiones $\mathrm{y}$ trabajos futuros.

\section{Materiales y métodos}

En los siguientes apartados se detalla el montaje experimental diseñado para la captura de las imágenes de las muestras utilizadas, los métodos de procesamiento de imágenes empleados y el algoritmo de clasificación utilizado. 


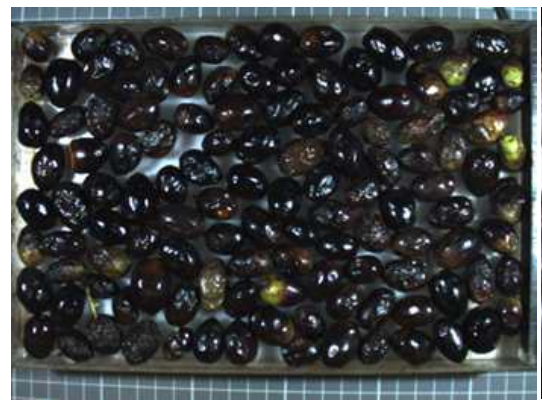

a)

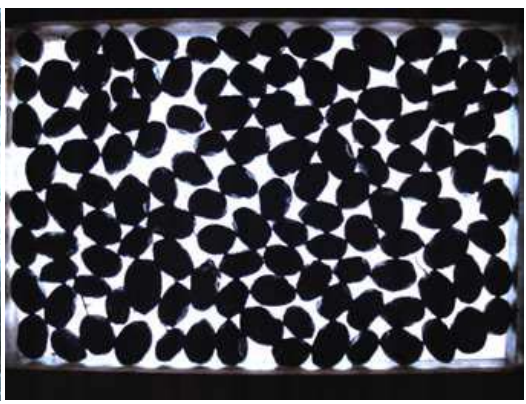

b)

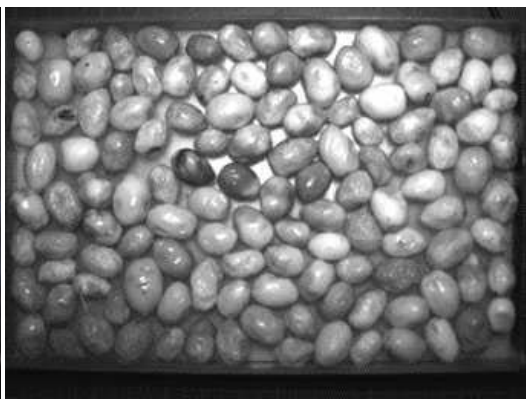

c)

Figura 2: Imágenes adquiridas con diferentes sistemas de iluminación: (a) focos led, (b) retroiluminación y (c) iluminación infrarroja

\subsection{Montaje experimental}

Las imágenes de los lotes de aceitunas empleados para la experimentación que se describe en este trabajo se adquirieron mediante un montaje experimental diseñado para tal fin. Éste se compone de un PC para capturar y guardar las imágenes, una cámara multi espectral CCD modelo JAI AD080-GE con doble sensor, para adquirir imágenes en el espectro visible y en el infrarrojo a $800 \mathrm{~nm}$, con una resolución de 1024 (horizontal) x 768 (vertical) por canal y 4 sistemas de iluminación, siendo éstos 2 focos LED de iluminación blanca de $20 \mathrm{~W}$, un sistema rectangular de iluminación infrarroja y un sistema de retroiluminación de $10 \mathrm{~W}$.

Cada uno de los lotes de aceitunas bajo inspección se ubicaron en un soporte rectangular de plástico de $25 \times 16.5 \times 2 \mathrm{~cm}$ y fondo transparente, que se colocó entre el sistema de retroiluminación y la cámara de visión. Tanto el procesado de imágenes como el software de análisis estadístico se programaron en Matlab bajo el SO Windows 7. En la Figura 1 se muestra un esquema del montaje experimental diseñado, una imagen real del mismo y algunos detalles tales como el sistema de retroiluminación activo, la cámara empleada y el panel LED infrarrojo empleado.

La elección del sistema de iluminación, de la cámara de visión y la disposición de los diferentes elementos en el montaje experimental se realizaron de forma experimental. El sistema de retroiluminación fue interesante para poder segmentar las aceitunas bajo inspección de forma individual. Por otro lado, mediante inspección visual, se detectó que tanto la presencia de defectos sobre la piel de la aceituna como las arrugas sobre la misma piel se contrastaban mejor con el sistema de visión y de iluminación en el infrarrojo. Además, las aceitunas deshidratadas provenientes del suelo aparentemente se diferenciaban mejor en el canal infrarrojo. Por otro lado, el número y la distribución de los focos LED se seleccionó con el fin de evitar problemas de saturación del sensor de visión por la presencia de brillos al incidir la iluminación sobre la superficie del fruto.

Las imágenes de las aceitunas se capturaron en estático y el número de alícuotas (muestras tomadas de cada lote) por lote fue función del tamaño de las aceitunas, con un promedio de 4 alícuotas por lote. En definitiva el número total de imágenes capturadas fue de 435 , de las cuales 223 correspondieron a aceitunas recolectadas del suelo y 212 del árbol. En cada imagen entraron una media de 104 aceitunas y para cada alícuota de aceitunas se obtuvieron 3 capturas secuenciadas automáticamente empleando los siguiente sistemas de iluminación en orden:

- Iluminación LED.

- Iluminación IR.

- Retroiluminación.

La Figura 2 muestra 3 capturas de la misma alícuota, una por cada sistema de iluminación empleado.

\subsection{Muestras empleadas}

Los experimentos se llevaron a cabo empleando capturas de aceitunas recogidas en patio de almazara durante la campaña de recolección 2014-2015 en la región de Montefrio (Granada), España. Las principales variedades de aceituna de la región son Picudo, Picual y Hojiblanco, aunque la variedad no se consideró en el estudio por falta de información. Para el estudio que se describe en este trabajo se emplearon 100 lotes de aceitunas, de los cuales $50 \%$ procedían directamente del suelo y $50 \%$ de árbol.

Una vez adquiridas las imágenes de cada una de la muestras éstas se enviaron a un laboratorio de análisis químico acreditado con el fin de analizar 


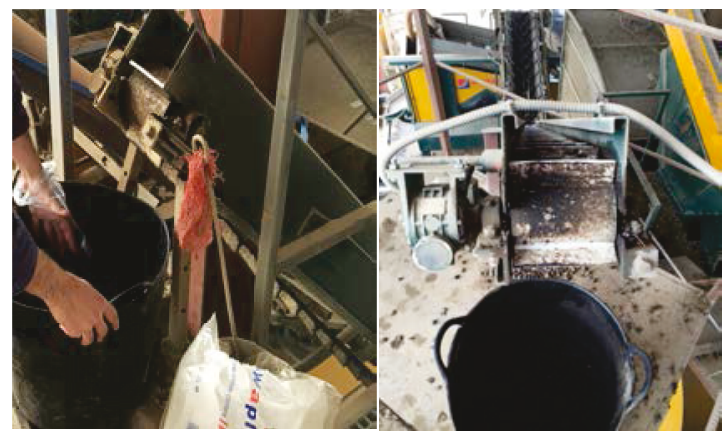

Figura 3: Procedimiento de recolección de muestras empleando un tomamuestras instalado en una de las líneas de la almazara

la calidad del aceite extraído de cada muestra de aceitunas. El aceite de oliva fue extraído por medio del sistema Abencor y los parámetros acidez e índice de peróxidos fueron analizados empleando para ello diferentes procedimientos analíticos estandarizados [6]. En la Tabla 1 se muestran los valores máximos, mínimos y medios que se obtuvieron tras este análisis.

Cuadro 1: Parámetros de calidad de las muestras empleadas

\begin{tabular}{lllll}
\hline \hline Muestra & \multicolumn{3}{l}{ Parámetro Media } & Máximo Mínimo \\
\hline \hline Lotes de & Acidez & 7.96 & 2.18 & 14.48 \\
\cline { 2 - 5 } $\begin{array}{l}\text { aceituna } \\
\text { de suelo }\end{array}$ & $\begin{array}{l}\text { Indice } \\
\text { Peróxidos }\end{array}$ & 36.04 & 15.50 & 78.80 \\
\hline \hline $\begin{array}{l}\text { Lotes de } \\
\text { aceituna }\end{array}$ & Acidez & 0.46 & 0.20 & 1.79 \\
\cline { 2 - 5 } de árbol & Peróxidos & 4.62 & 0.20 & 9.10 \\
\hline \hline $\begin{array}{l}\text { Total de } \\
\text { lotes }\end{array}$ & Acidez & 4.31 & 0.20 & 14.48 \\
\cline { 2 - 5 } & $\begin{array}{l}\text { Índice } \\
\text { Peróxidos }\end{array}$ & 20.73 & 0.20 & 74.80 \\
\hline \hline
\end{tabular}

$\overline{\text { Acidez expresada en porcentaje de ácido oleico libre; }}$ Índice de peróxidos expresado en miliequivalentes de oxígeno activo por kilo de grasa

\subsection{Análisis de imágenes}

Las características que identifican a cada una de las dos clases de aceitunas consideradas en este estudio se pueden determinar observando directamente el color y la textura de la piel del fruto de imágenes de cada una de las dos clases. Por un lado las aceitunas de árbol son generalmente verdes, moradas o negras según el índice de madurez y de piel tersa. Normalmente estas características identifican aceitunas sanas que en condiciones normales de proceso pueden producir aceite de oliva con bajo grado de acidez y bajo índice de peróxidos. Por otro lado, las aceitunas recolectadas del suelo suelen presentar tonos amarronados y piel arrugada a causa del proceso de deshidratación que sufre el fruto cuando éste deja de estar unido al árbol. De las aceitunas con un alto porcentaje de defectos, secas, arrugadas y con tonos amarronados normalmente se obtienen aceites con altos grados de acidez y elevados índices de peróxidos.

En primer lugar las aceitunas contenidas en cada una de las imágenes capturadas se segmentaron para considerar únicamente las características presentes sobre la piel de la aceituna. En otros trabajos, como el referenciado en [15], los autores también trabajaron con aceitunas segmentadas para encontrar defectos sobre la superficie del fruto. El procedimiento de segmentación se desarrolló como se explica a continuación. Cada una de las imágenes adquiridas empleando el sistema de iluminación basado en retroiluminación se procesó morfológicamente con la función imopen de la toolbox de procesamiento de imágenes de Matlab. Esta función consiste en una operación de erosión seguida de una operación de dilatación, utilizando como elemento estructurante uno de tipo ball (ver [16] para más detalles acerca de esta operación). Posteriormente las imágenes fueron binarizadas mediante una segmentación por umbralización basada en histograma. De este modo se segmentaron las aceitunas del fondo de las imagen.

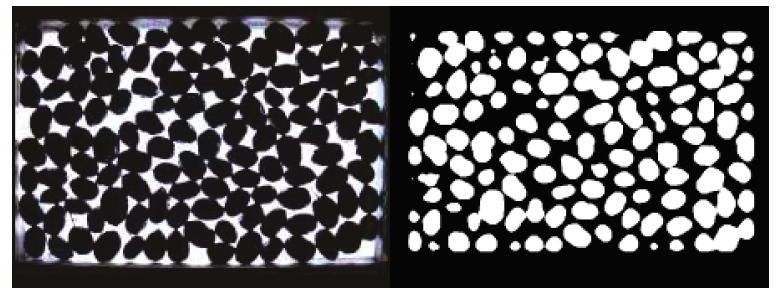

a)

b)

Figura 4: Imágenes para la segmentación de aceitunas donde (a) es la imagen original adquirida empleando el sistema de retroiluminación y (b) es la imagen procesada donde las aceitunas (en blanco) han sido detectadas

En la Figura 4 se muestra un ejemplo de imagen capturada empleando el sistema de retroiluminación y la misma imagen después de aplicar el procesado descrito anteriormente.

Posteriormente, el tamaño de cada una de las imágenes fue redimensionado para considerar únicamente el área de la imagen con contenido de aceitunas. A continuación las imágenes fueron transformadas al espacio de color del CIE Lab [17] para contrastar los tonos verdes y amarronados de la superficie de las aceitunas por un lado. Por el otro se emplearon las imágenes capturadas en el espectro del infrarrojo para determinar características relacionadas con la textura de las aceitunas tales como presencia de aceitunas con piel arrugada y defectos en su superficie. 


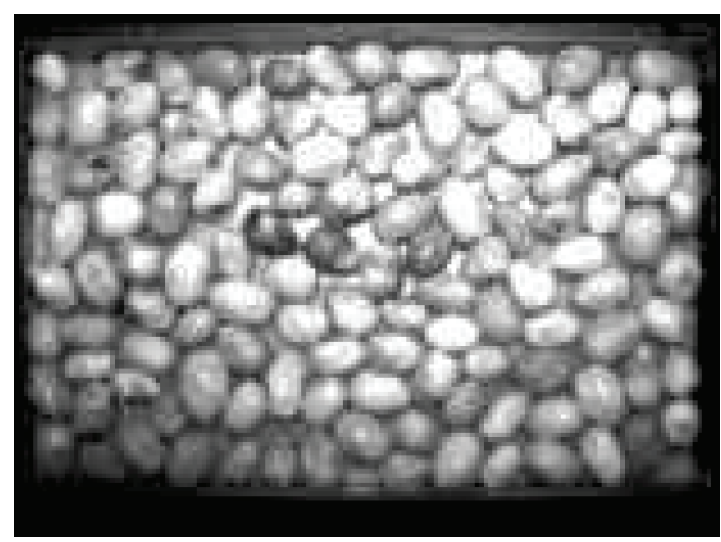

a)

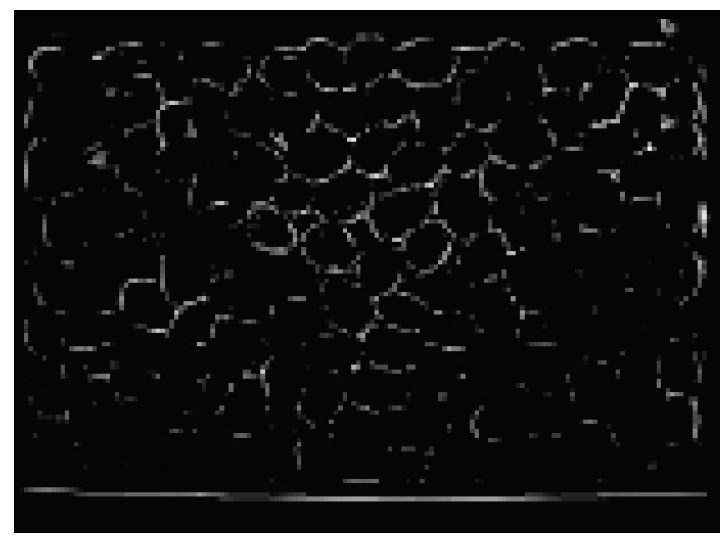

b)

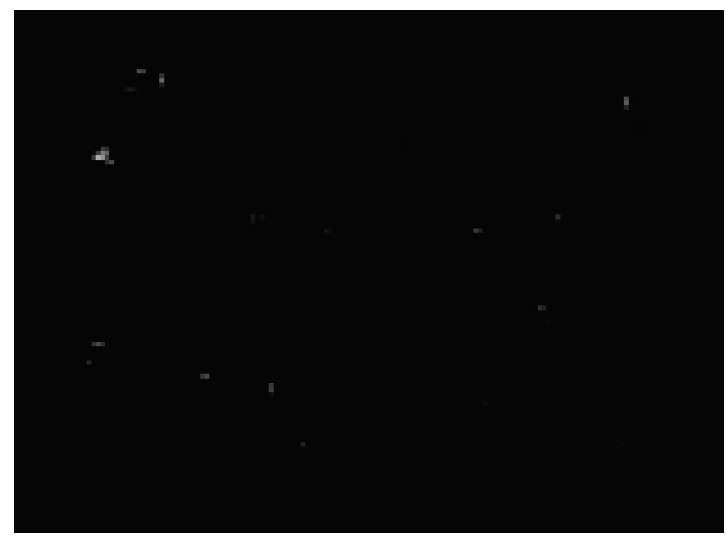

c)

Figura 5: Procesado de imagen para la determinación de la textura donde (a) es la imagen original en el canal infrarrojo, (b) es la imagen de textura una vez aplicado el filtro y (c) es la imagen de textura después de eliminar los bordes de las aceitunas
Además, para contrastar la presencia de imperfecciones sobre la piel de la aceituna se aplicó el algoritmo de umbralización de Bradley sobre las imágenes capturadas en el canal infrarrojo [18]. De forma resumida el algoritmo consiste en comparar el nivel de gris de cada pixel de la imagen con el de los píxeles vecinos y como resultado se obtiene una imagen de textura. Si el nivel de gris del pixel evaluado es un porcentaje $T$ inferior al promedio de los píxeles vecinos contenidos en un cuadrado de tamaño de lado $S$, el valor del mismo pixel en la imagen de textura será 0 . En otro caso será 1 . En nuestro caso los valores de $\mathrm{T}$ y $\mathrm{S}$ se ajustaron experimentalmente siendo $T$ igual a $15 \%$ y $S$ igual a 10 píxeles. El procesado descrito permite detectar la presencia de arrugas en la piel, imperfecciones y también el borde de la aceituna. Este último no es interesante para el objetivo del estudio así que se eliminó enmascarando los bordes con la imagen previamente segmentada. La Figura 5 muestra un ejemplo de la imagen original (a) procesada con Bradley (b) y con los bordes de las aceitunas eliminados (c). En la misma imagen se puede ver como los cambios abruptos de intensidad en la piel de aceituna y los defectos han sido detectados (ambos representados en color blanco). La metodología descrita se implementó empleando la toolbox de procesamiento de imágenes de Matlab (http://es.mathworks.com/help/images/).

Para detectar la presencia de tonos verdes y amarronados sobre las aceitunas se procesaron las imágenes capturadas en el espectro visible. Del mismo modo que para la determinación de la textura, la región de interés de cada imagen fue obtenida utilizando como máscara la imagen binarizada obtenida mediante retroiluminación. A continuación las imágenes se transformaron al espacio de color CIELab empleando la función rgb2lab de la toolbox de procesamiento de imágenes de Matlab y dando como resultado tres canales $L, a$ y $b$. En este espacio de color el canal $L$ representa la luminancia del color; el canal $a$ codifica el tono de color verde y rojo (valores negativos indican dominio del color verde y valores positivos de rojo) y el canal $b$ codifica la presencia de tonos azules y amarillos en la imagen (valores negativos indican dominio del color azul y valores positivos de color amarillo). Mientras que el canal $L$ no aporta información para el objetivo del estudio de este trabajo, los canales $a$ y $b$ si se consideraron interesantes para caracterizar el estado de la aceituna. La Figura 6 muestra un ejemplo de imagen capturada en el espectro visible y después de transformarla a CIELab.

Tras la metodología descrita se obtuvieron tres parámetros para cada una de las imágenes capturadas: 


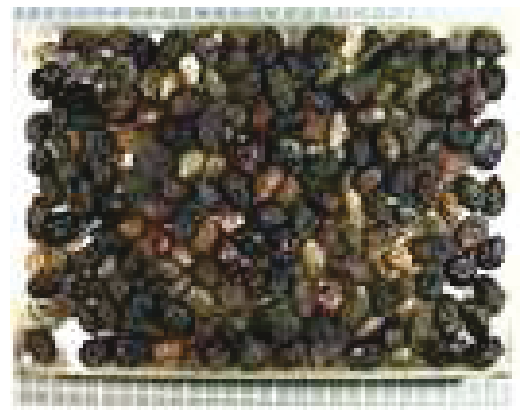

a)

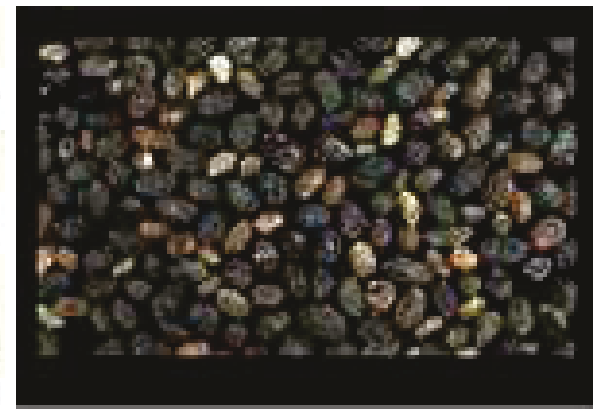

b)

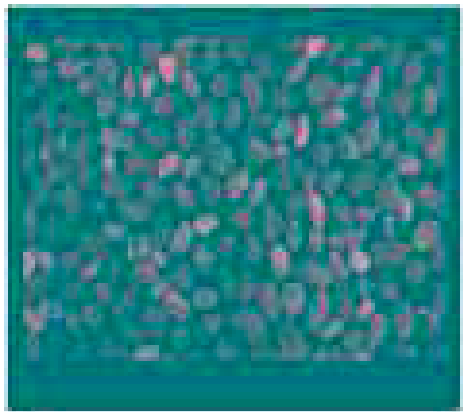

c)

Figura 6: Imágenes para la evaluación del color donde (a) es la imagen original, (b) muestra las aceitunas segmentadas y (c) la misma imagen en el espacio CIELab

- Parámetro a: intensidad media de nivel de gris del canal a ponderado con el número de píxeles que comprenden el área con presencia de aceitunas.

- Parámetro b: intensidad media de nivel de gris del canal $b$ ponderado con el número de píxeles que comprenden el área con presencia de aceitunas.

- Parámetro índice de textura TI: total de píxeles con valor 1 en la imagen de textura ponderado con el número de píxeles que comprenden el área con presencia de aceitunas.

\subsection{Algoritmos de aprendizaje y estimación}

Como algoritmo de aprendizaje y de estimación de la acidez libre y del índice de peróxidos en muestras de aceitunas se implementaron dos redes neuronales (ANN), cada una con dos capas y de tipo feed-forward como método de estimación no lineal. Los parámetros de configuración para cada una de las redes neuronales implementadas fueron los mismos.

Se empleó una capa oculta con tres nodos de entrada uno por parámetro considerado: índice de textura TI, intensidad promedia en el canal $a$ e intensidad promedia en el canal $b$. El número de neuronas de la capa oculta se seleccionó experimentalmente y con 10 neuronas se obtuvieron buenos resultados. Finalmente la capa de salida se configuró con un nodo de salida (ver Figura 7).

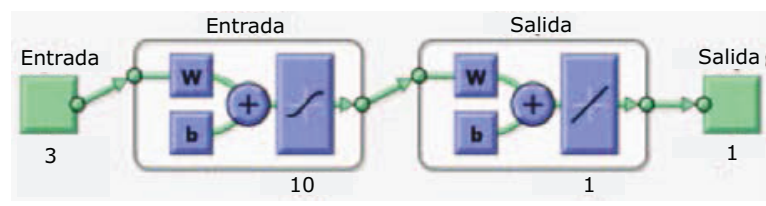

Figura 7: Configuración de las ANN programadas
Las ANN implementadas se entrenaron con el algoritmo de propagación hacia atrás LevenbergMarquardt ya que es eficiente en problemas de regresión [19]. La función de activación de la capa oculta fue de tipo sigmoidal mientras que las funciones de activación de la capa de salida fue de tipo lineal. Para la implementación, entrenamiento y validación de las ANN se empleó la toolbox de redes neuronales de Matlab (http://es.mathworks.com/help/nnet/).

\section{Resultados experimentales}

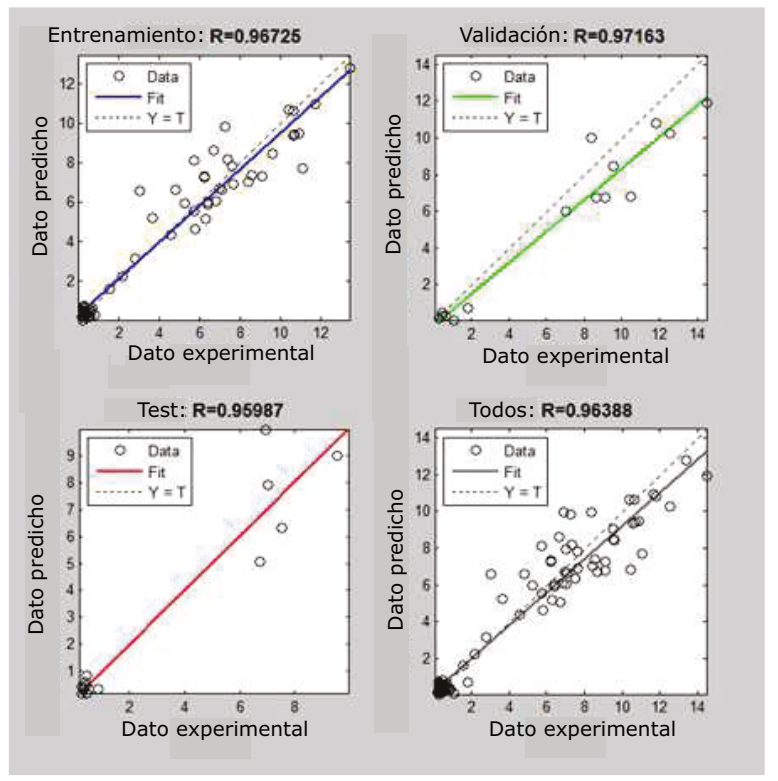

Figura 8: Porcentaje de ácido oleico estimado empleando la red neuronal configurada donde Target representa las medidas obtenidas por el laboratorio y Output son los valores estimados por la red

Las dos ANN configuradas se entrenaron empleando los tres parámetros a, b y TI obtenidos a partir del procesamiento de las imagenes capturadas por el sistema de visión configurado. Una de ellas se 
entrenó para predecir la acidez del aceite producido y la otra para estimar el índice de peróxidos sobre las mismas muestras. En total se capturaron 435 imágenes de las cuales el $70 \%$ de ellas se emplearon para entrenar la ANN, el $15 \%$ para el proceso de validación y el $15 \%$ restante para predicción.

Las Figuras 8 y 9 muestran las rectas de regresión para los resultados obtenidos en fase de entrenamiento, validación y predicción. La Figura 8 muestra los resultados para la estimación de acidez con un coeficiente de regresión de 0.96, mientras que la Figura 9 muestra los mismos resultados para la estimación del índice de peróxidos. En este caso el coeficiente de regresión fue de 0.939.

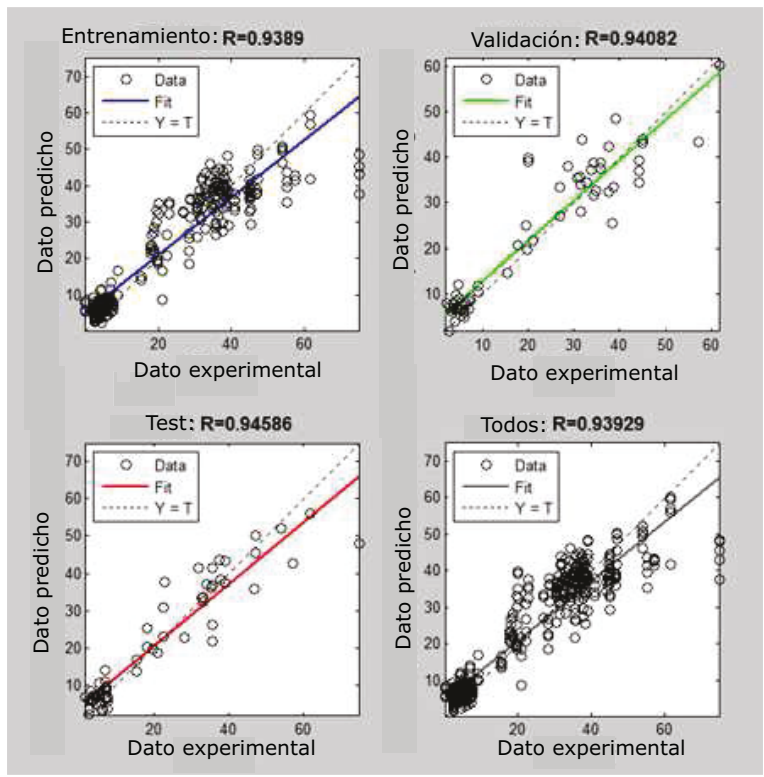

Figura 9: Índice de peróxidos estimado empleando la red neuronal configurada donde Target representa las medidas obtenidas por el laboratorio y Output son los valores estimados por la red

\section{Conclusiones y trabajos futuros}

Se ha desarrollado e implementado una metodología basada en visión por computador para la estimación automática de la calidad del aceite de oliva virgen de forma previa a su elaboración. El procedimiento implementado permite predecir el índice de peróxidos y la acidez de lotes de aceitunas recolectadas del árbol o recogidas del suelo. Para ambos casos se configuraron dos redes neuronales como algoritmo de aprendizaje y estimación.

Con coeficientes de regresión de 0.963 para acidez y 0.939 para peróxidos se ha demostrado que el procedimiento implementado es interesante para ser aplicado directamente en almazaras en la fase de recepción de aceitunas para la predicción automática de la calidad del aceite elaborado.

Como trabajo futuro podría ser interesante validar el mismo procedimiento bajo condiciones reales de almazara con aceitunas en movimiento. Predecir la calidad del aceite elaborado puede ser interesante para clasificar la aceituna de entrada en las almazaras y para ajustar los parámetros del proceso en función de la máxima calidad alcanzable.

\section{Agradecimientos}

Este trabajo ha sido parcialmente financiado por los proyectos DPI2011-27284 y AGR-6616.

\section{Referencias}

[1] International Olive Council, "103nd session of the IOOC," Madrid, Spain, Tech. Rep., 2015.

[2] L. Di Giovacchino, S. Sestili, and D. Di Vincenzo, "Influence of olive processing on virgin olive oil quality," European Journal of Lipid Science and Technology, vol. 104, no. 9-10, pp. 587-601, oct 2002.

[3] P. Cano Marchal, D. M. Martinez Gila, J. Gamez Garcia, and J. Gomez Ortega, "Optimal Production Planning for the Virgin Olive Oil Elaboration Process," in Proceedings of the 19th IFAC World Congress, 2014, B. Edward, Ed., 2014, pp. 89218926. [Online]. Available: http://www.ifacpapersonline.net/Detailed/68079.html

[4] P. Cano Marchal, J. Gomez Ortega, D. Aguilera Puerto, and J. Gamez Garcia, "Situación actual y perspectivas futuras del control del proceso de elaboración del aceite de oliva virgen," Revista Iberoamericana de Automática e Informática Industrial RIAI, vol. 8, no. 3, pp. 258-269, jul 2011.

[5] D. Barranco Navero, R. Fernandez Escobar, and L. Rallo Romero, El cultivo del olivo, 6th ed., Mundi-Prensa, Ed., Madrid, Spain, 2008.

[6] European Union, "Commission Implementing Regulation (EU) No. 1348/2013 amending Regulation (EEC) No 2568/91 on the characteristics of olive oil and olive-residue oil and on the relevant methods of analysis," Off. J. Eur. Union, vol. 31, 2013.

[7] M. Uceda, "Trends in olive oil production Olive oil extraction and quality," Grasas y Aceites, vol. 57, no. 1, pp. 25-31, 2006.

[8] B. Jimenez Herrera and A. Crapio Duenas, "La cata de aceites: Aceite de oliva virgen. 
Caracteristicas organolepticas y analisis sensorial," IFAPA, Junta de Andalucia, Seville, Spain, Tech. Rep., 2008.

[9] Brosnan and Sun, "Improving quality inspection of food products by computer vision: a review," Journal of Food Engineering, vol. 61, no. 1, pp. 3-16, jan 2004.

[10] R. Diaz, L. Gil, C. Serrano, M. Blasco, E. Moltó, and J. Blasco, "Comparison of three algorithms in the classification of table olives by means of computer vision," Journal of Food Engineering, vol. 61, no. 1, pp. 101107, jan 2004.

[11] T. Ram, Z. Wiesman, I. Parmet, and Y. Edan, "Olive oil content prediction models based on image processing," Biosystems Engineering, vol. 105, no. 2, pp. 221-232, feb 2010.

[12] R. Furferi, L. Governi, and Y. Volpe, "ANNbased method for olive Ripening Index automatic prediction," Journal of Food Engineering, vol. 101, no. 3, pp. 318-328, dec 2010.

[13] E. Guzmán, V. Baeten, J. A. Fernández, and J. a. García-Mesa, "Infrared machine vision system for the automatic detection of olive fruit quality," Talanta, vol. 116, pp. 894-898, nov 2013.

[14] D. Martinez Gila, D. Aguilera Puerto, J. Gamez Garcia, and J. Gomez Ortega, "Automatic classification of olives for oil production using computer vision," in 2015 IEEE International Conference on Industrial Technology (ICIT). IEEE, mar 2015, pp. 1651-1656.

[15] M. Riquelme, P. Barreiro, M. Ruiz-Altisent, and C. Valero, "Olive classification according to external damage using image analysis," Journal of Food Engineering, vol. 87, no. 3, pp. 371-379, aug 2008.

[16] R. C. Gonzalez, R. E. Woods, and S. Eddins, "Morphological Image Processing," in Digital Image Processing Using MATLAB, 2nd ed. Gatesmark Publishing, 2009, pp. 334-378.

[17] C.I.E., "Central Bureau of the Commission Internationale de LEclairage," Viena, Tech. Rep., 2008.

[18] D. Bradley and G. Roth, "Adaptive Thresholding using the Integral Image," Journal of Graphics, GPU, and Game Tools, vol. 12, no. 2, pp. 13-21, jan 2007.
[19] M. Hagan and M. Menhaj, "Training feedforward networks with the Marquardt algorithm," IEEE Transactions on Neural Networks, vol. 5, no. 6, pp. 989-993, 1994. 